\title{
Predictive Factors of Histological Response after Preoperative Concomitant Radiochemotherapy in Middle and Low Rectal Cancer
}

\author{
Asmae Ouabdelmoumen', Ali Sbai' ${ }^{1}$, Fouad Elmejjatti' ${ }^{1}$, Zohour Bourhaleb ${ }^{2}$, \\ Naima Abda ${ }^{3}$, Loubna Mezouar ${ }^{1}$
}

\begin{abstract}
${ }^{1}$ Departement of Radiotherapy, Center of oncology HassanII, University Hospital MOHAMED VI, km 8 route Jerada, BP:2013, Oued Ennachef, 60000 Oujda, Morocco. ${ }^{2}$ Departement of Radiotherapy, University Hospital IBN ROCHD, quartier des Hôpitaux, rue Sebta, 20360 Casablanca, Morocco. ${ }^{3}$ Laboratory of Epidemiology and Public Health, Medical Faculty of Oujda, Mohammed Premier University, Morocco.
\end{abstract}

\begin{abstract}
Objective: The aim of our study was to identify potential predictive factors beyond pathologic response after neoadjuvant radiochemotherapy. Patients and Methods: Between January 2009 and December 2014, 40 patients with rectal carcinoma were included in the study. The treatment consisted of radiation ranging between 39 and 50.4 Gy associated with a concomitant chemotherapy with capecitabine. The correlation between histological response (complete response and downstaging) and potential predictive factors were investigated. Results: Complete response was $15 \%$ (06 patients), tumor regression of 32.5\% (13 patients), and the absence of tumor response of $52.5 \%$ (21 patients). In univariate analysis, the circumferential extension of the tumor was significantly associated with tumor downstaging $(p=0.007)$ and complete tumor response $(p=0.001)$. However, the delay between the RCT and the surgery was a significant predictor for downstaging $(p=0.02)$. Conclusion: the parietal circumferential extension was a potential predictor of pathologic complete response (PCR) and downstaging after neoadjuvant chemoradiation. The time between the radiochemotherapy and the surgery was a significant predictor for downstaging. Delaying surgery beyond 8 weeks seems to result in the highest probability of PCR.
\end{abstract}

Keywords: Rectal cancer- adenocarcinoma- neoadjuvant radiochemotherapy- histologic response- predictive factors

Asian Pac J Cancer Care, 3 (3), 65-70

\section{Introduction}

Colorectal cancer (CRC) is the fourth most fre $\neg$ quently diagnosed malignancy in both sexes and the second most common cause of cancer death in the world [1]. The advent of neoadjuvant radiotherapy in association with TME (Total Mesorectal Excision) surgery described by RJ Heald in 1982 [2]. has transformed the management of locally advanced forms (T3 T4 and/or $\mathrm{N}+$ ) of middle and low rectal cancer, with a significant gain on local recurrence and an improvement in overall survival [3]. The association of chemotherapy with radiotherapy has further improved the carcinological and functional prognosis of this disease, favoring tumor regression (downstaging) or even tumor sterilization in some cases [4]. An interval of six to eight weeks between the end of
Submission Date: 06/23/2018Ａcceptance Date: 08/26/2018

radiochemotherapy (RCT) and surgery is recommended to optimize this tumor response and minimize toxicity [5]. In the literature, the tumor response correlates with recurrence-free survival and overall survival [6]. However, not all patients have the same sensitivity to this RCT: some tumors may not respond well to this treatment when others respond well.

The aim of this retrospective study was to identify the potential clinical, pathological, and therapeutic that could predict tumor response (complete pathologic response or downstaging to neoadjuvant RCT.

\section{Materials and Methods}

Between January 2009 and December 2014, 90 patients underwent preoperative RCT at the radiotherapy

Corresponding Author:

Dr. Asmae Ouabdelmoumen

Departement of Radiotherapy, Center of oncology HassanII, University Hospital MOHAMED VI, km 8 route Jerada, BP:2013, Oued Ennachef, 60000 Oujda, Morocco.

Email: moumen.asmae@gmail.com 
department at University Hospital Mohamed VI, Oujda, Morocco.

\section{Inclusion criteria for this study were included}

biopsy-proven rectal cancer, the tumor of the lower and middle rectum, classified as CT3-T4 with or without regional lymph node metastasis and no evidence of distant metastasis. Among reviewed 90 patients, 50 patients were excluded for the following reasons: patients had no curative surgery (the tumor is unresectable or the patients refuse surgery), and patients who were transferred to other hospitals could not be traced by medical records. Therefore, 40 patients who met the inclusion criteria were analyzed in this study.

Patients underwent Pre-therapeutic staging workups, including digital rectal examination, full blood counts, biochemical tumor markers (but the concentration of pre-therapeutic ACE was not routinely required in all patients), colonoscopy with biopsy, chest radiography, abdominopelvic computed tomography (CT), pelvic magnetic resonance imaging (MRI). Endorectal ultrasonography (ERUS) was executed for one patient. The preoperative clinical stage was determined by CT scan, MRI, physical examination, or a combination of these.

Clinical and pathological characteristics of a population are described in Table 1 . The study population was mostly females $(57.5 \%)$ and had a median age of 56 years (range, 33 to 84 years). All the patients had a tumor within $10 \mathrm{~cm}$ from the anal verge: $57.5 \%$ of the tumors were in the lower rectum and $42.5 \%$ in the middle rectum. The tumors had involved more than $50 \%$ of the rectal circumference in $32.5 \%$ of the cases. During a digital rectal examination, the tumor was fixed in $25 \%$. Almost all patients had a cT3 classification of their primary tumor $(95 \%)$,

The patients then received preoperative CRT in the form of preoperative whole-pelvis radiotherapy. The mean dose was $46 \mathrm{~Gy}$ (range, 39 to $50 \mathrm{~Gy}$ ): $15 \%$ of the patients received hypofractionated radiotherapy with the dose of $39 \mathrm{~Gy}$ in 13 fractions, 35\% received $46 \mathrm{~Gy}$ in 23 fractions and $50 \%$ received 50 Gy in 25 fractions with a sequential boost of 4 Gy. All patients underwent CT simulation for three-dimensional radiotherapy planning. Delineation of the clinical target volume (CTV) included the gross tumor volume, mesorectum, presacral space, whole of the sacral hollow and regional lymphatics. The boost CTV included the gross tumor volume with $1 \mathrm{~cm}$ margins. The relevant organs at risk volumes for this study were the bladder, femoral bones, and small bowel. The 6-MV or 18-MV photon beams were used for the treatment plan. Dosimetric parameters were calculated using cumulative dose volume histogram data. Preoperative chemotherapy was initiated on the first day of pelvic radiotherapy and was delivered concurrently with radiotherapy. All patients received $825 \mathrm{mg} / \mathrm{m}^{2}$ capecitabine orally twice daily, over the duration of radiotherapy with weekend breaks [7]. At the range of 32 to 137 days after the completion of preoperative RCT, all patients underwent a proctectomy associated with total mesorectal excision, with or without sphincter preservation. Anterior resection was performed in 19 patients $(47.5 \%)$ and abdominoperineal resection in 21 patients $(52.5 \%)$.

Histological examination of the operative specimen was performed to assess tumor type, histologic grade, number of retrieved and invaded LNs, maximum cir $\neg$ cumferential, distal extent, venous or perineural invasion, definitive staging (ypTNM after neoadjuvant treatment) evaluated according to the seventh edition of the UICC classification [8]. Tumor regression grading (TRG) was done according to Dworak et al. (Table 2) [8].

As previously used and validated in one study, the tumor response, whether complete or partial (downstaging), was characterized by a reduction in pathological staging (yp Stage) relative to the pre-therapeutic stage (c Stage) [9]. We defined the complete histological response as the total absence of tumor cells on the operative pathologic specimen at both the primary site and in regional LNs (ypT0 N0), grade 4 of the Dworak classification (Table 2) $[9,10]$. The downstaging was defined as the lowering of the $\mathrm{T}$ classification to a stage less than or equal to ypT2.

A univariate analysis was done by the log-rank test. This analysis consists in studying the complete response and downstaging, after neoadjuvant treatment in middle and lower rectal cancer, as a function of various potential predictors factors: age, sex, circumferential extent of tumor, tumor fixation, Distance from anal verge, Tumor differentiation, hemoglobin level, clinical T classification, clinical lymph node $(\mathrm{N})$ classification, radiation dose, and time between RCT and surgery. Multivariate analysis could not be done due to the lack of power due to low numbers. The analysis was performed with IBM SPSS statistics trial ver. 20.0 (IBM, Armonk, NY, USA). A p-value of $<0.05$ was considered to indicate a significant difference.

\section{Results}

Pathologic examination of resected specimens revealed a complete histopathological response (PCR) in 06 patients (15\%). Downstaging to ypT2 or less was observed in 19 patients $(47,5 \%)$. Twenty-one patients $(52,5 \%)$ showed no downstaging of either $\mathrm{T}$ or $\mathrm{N}$ stage and were classified as non-responders (Table 3 ). The tumor was classified as ypT0 in 6 patients $(15 \%)$, ypT1 in $4(10 \%)$, ypT2 in $9(22.5 \%)$, ypT3 in $19(47.5 \%)$ and ypT4 in two (5\%).

The univariate analysis indicated that the circumferential extent of the tumor was significantly associated with tumor downstaging $(\mathrm{p}=0.007)$ and with a complete tumor response $(p=0.001)$. However, a delay between RCT and surgery $\geq 8$ weeks was a significant predictive factor for downstaging $(\mathrm{p}=0.02)$. Other variables (sex, age, Tumor localization, tumor fixation, anemia, Distance from the anal verge, Tumor differentiation, clinical $\mathrm{T}$ classification, clinical lymph node $(\mathrm{N})$ classification, radiation dose) were not significantly correlated with downstaging (Table 4 and 5). 
Table 1. Clinical and Pathological Characteristics of Patients

\begin{tabular}{|c|c|c|}
\hline & & Results \\
\hline \multirow[t]{2}{*}{ Sex } & Male & $17(42.5 \%)$ \\
\hline & Female & $23(57.5 \%)$ \\
\hline Age & Mean [min-max] & $56.4[33-84]$ \\
\hline \multirow[t]{2}{*}{ Circumferential extent } & $\leq 50 \%$ & $27(67.5 \%)$ \\
\hline & $>50 \%$ & $13(32.5 \%)$ \\
\hline \multirow[t]{2}{*}{ Fixation } & fixed & $10(25 \%)$ \\
\hline & Not fixed & $30(75 \%)$ \\
\hline \multirow[t]{2}{*}{ Distance from anal verge } & Middle rectum & $17(42.5 \%)$ \\
\hline & Lower rectum & $23(57.5 \%)$ \\
\hline \multirow[t]{2}{*}{ hemoglobin level $<12 \mathrm{~g} / \mathrm{dl}$} & Yes & $21(52.5 \%)$ \\
\hline & No & $19(47.5 \%)$ \\
\hline \multirow[t]{3}{*}{ Tumor differentiation } & Well & $22(55 \%)$ \\
\hline & Moderate & $18(45 \%)$ \\
\hline & Poor & $4(10 \%)$ \\
\hline \multirow[t]{2}{*}{ Clnical T stage } & $\mathrm{T} 3$ & $38(95 \%)$ \\
\hline & $\mathrm{T} 4$ & $2(5 \%)$ \\
\hline \multirow[t]{2}{*}{ Clnical N stage } & No & $26(65 \%)$ \\
\hline & $\mathrm{N}+$ & $14(35 \%)$ \\
\hline
\end{tabular}

Table 2. Dworak Regression Grade [9]

\begin{tabular}{lc}
\hline Grade 0 & No regression \\
\hline Grade 1 & Dominant tumor mass with obvious fibrosis and/or vasculopathy \\
Grade 2 & Dominantly fibrotic changes with few tumor cells or groups (easy to find) \\
Grade 3 & Very few (difficult to find microscopically) tumor cells in fibrotic tissue with or without mucous substance. \\
Grade 4 & No tumor cells, only fibrotic mass (total regression or response) \\
\hline
\end{tabular}

Table 3. Comparison between Pre Treatment Radiological TN Stage and Post Treatment Pathological Stage (ypT ypN stage).

\begin{tabular}{lccccccccccc}
\hline PRE $(\mathrm{cTN})$ & \multicolumn{1}{c}{ POST $(\mathrm{ypTN})$} & \multicolumn{1}{c}{ TOTAL } \\
\hline & T0N0 & T0N+ & T1N0 & T1N+ & T2N0 & T2N+ & T3N0 & T3N+ & T4N0 & T4N+ \\
T3N0 & 4 & 0 & 0 & 2 & 7 & 0 & 6 & 6 & 0 & 0 & 25 \\
T3N+ & 2 & 0 & 2 & 0 & 0 & 2 & 3 & 4 & 0 & 0 & 13 \\
T4N0 & 0 & 0 & 0 & 0 & 0 & 0 & 0 & 0 & 1 & 0 & 1 \\
T4N+ & 0 & 0 & 0 & 0 & 0 & 0 & 0 & 0 & 0 & 1 & 1 \\
TOTAL & 6 & 0 & 2 & 2 & 7 & 2 & 9 & 10 & 1 & 1 & 40 \\
\hline
\end{tabular}

\section{Discussions}

The factors that predict the response to neoadjuvant radiation chemotherapy in rectal cancer has not yet been well determined. Some recent studies also have investigated potential predictors of PCR and downstaging.

Tumor circumference can serve as an important predictor of pathological tumor response. This was demonstrated in the study by Das et al. [11]. In this study, the results of the univariate and multivariate analysis indicate that the circumferential extent of tumor (less than $60 \%$ ) predicts significantly the complete response rate and downstaging. These results agree with those of our study, the circumferential extent of a tumor was significantly predicted for PCR and downstaging with a $p$ of 0.001 and 0.007 respectively.

The interval from the end of radiation to surgery has been of special interest and has been directly addressed by multiple studies as well as a meta-analysis [12]. Although the exact ideal interval to optimize PCR has not been identified, the overall conclusion from these studies is that PCR rates improve with delaying surgery by more than 6-8 weeks after the end of RCT. In this context, curative surgical treatments performed at six weeks from the end of the RCT may have interrupted ongoing necrosis, which means that some patients may achieve complete tumor regression if waiting times were longer [13]. Kalady et al. in 2009 [14] had shown that interval 
Table 4. Unifactorial Analysis of the Complete Histological Response

\begin{tabular}{|c|c|c|c|c|}
\hline \multicolumn{2}{|c|}{ Variables } & \multirow{2}{*}{$\frac{\mathrm{pCR}}{3}$} & \multirow{2}{*}{$\frac{\text { No pCR }}{4}$} & \multirow{2}{*}{$\begin{array}{c}\mathrm{P} \\
0.51\end{array}$} \\
\hline Sex & Male & & & \\
\hline & Female & 3 & 20 & \\
\hline Age & Mean [min-max] & $54.83[38-70]$ & $56.68[33-84]$ & 0.76 \\
\hline Circumferential extent & Mean [min-max] & $32.5[25-40]$ & $69.56[25-100]$ & 0.001 \\
\hline \multirow[t]{2}{*}{ Fixation } & Fixed & 1 & 9 & 0.52 \\
\hline & Not fixed & 5 & 25 & \\
\hline \multirow{2}{*}{ Distance from anal verge } & Middle rectum & 4 & 13 & 0.19 \\
\hline & Lower rectum & 2 & 21 & \\
\hline \multirow[t]{2}{*}{ hemoglobin level $<12 \mathrm{~g} / \mathrm{dl}$} & Yes & 2 & 19 & 0.28 \\
\hline & No & 4 & 15 & \\
\hline \multirow[t]{2}{*}{ Tumor differentiation } & Well & 3 & 19 & 0.56 \\
\hline & Moderate to poor & 3 & 15 & \\
\hline \multirow[t]{2}{*}{ Clnical T stage } & $\mathrm{T} 3$ & 6 & 32 & 0.71 \\
\hline & $\mathrm{T} 4$ & 0 & 2 & \\
\hline \multirow[t]{2}{*}{ Clnical N stage } & No & 4 & 22 & 0.65 \\
\hline & $\mathrm{N}+$ & 2 & 12 & \\
\hline \multirow[t]{2}{*}{ Radiation dose } & $<50 \mathrm{~Gy}$ & 3 & 17 & 0.66 \\
\hline & $\geq 50 \mathrm{~Gy}$ & 3 & 17 & \\
\hline \multirow[t]{2}{*}{ delay between RCT and surgery } & $<8$ semaines & 1 & 13 & 0.3 \\
\hline & $\geq 8$ semaines & 5 & 21 & \\
\hline
\end{tabular}

Table 5. Unifactorial Analysis of the Tumor Response (Downstaging)

\begin{tabular}{|c|c|c|c|c|}
\hline \multicolumn{2}{|l|}{ Variables } & \multirow{2}{*}{$\begin{array}{c}\text { Downstaging } \\
8\end{array}$} & \multirow{2}{*}{$\begin{array}{c}\text { No downstaging } \\
9\end{array}$} & \multirow{2}{*}{$\frac{P}{0.60}$} \\
\hline Sex & Male & & & \\
\hline & Female & 11 & 12 & \\
\hline Age & Mean [min-max] & $60.63[37-84]$ & $52.57[33-75]$ & 0.60 \\
\hline Circumferential extent & Mean [min-max] & $52.89[25-100]$ & $74.05[25-100]$ & 0.007 \\
\hline \multirow[t]{2}{*}{ Fixation } & fixed & 3 & 7 & 0.18 \\
\hline & Not fixed & 16 & 14 & \\
\hline \multirow[t]{2}{*}{ Distance from anal verge } & Middle rectum & 8 & 9 & 0.60 \\
\hline & Lower rectum & 11 & 12 & \\
\hline \multirow[t]{2}{*}{ hemoglobin level $<12 \mathrm{~g} / \mathrm{dl}$} & Yes & 7 & 14 & 0.58 \\
\hline & No & 12 & 7 & \\
\hline \multirow[t]{2}{*}{ Tumor differentiation } & Well & 9 & 13 & 0.27 \\
\hline & Moderate to poor & 10 & 8 & \\
\hline \multirow[t]{2}{*}{ Clnical T stage } & $\mathrm{T} 3$ & 19 & 19 & 0.26 \\
\hline & $\mathrm{T} 4$ & 0 & 2 & \\
\hline \multirow[t]{2}{*}{ Clnical N stage } & No & 13 & 13 & 0.46 \\
\hline & $\mathrm{N}+$ & 6 & 8 & \\
\hline \multirow[t]{2}{*}{ Radiation dose } & $<50 \mathrm{~Gy}$ & 9 & 11 & 0.50 \\
\hline & $\geq 50 \mathrm{~Gy}$ & 10 & 10 & \\
\hline \multirow[t]{2}{*}{ delay between RCT and surgery } & $<8$ weeks & 2 & 12 & 0.02 \\
\hline & $\geq 8$ weeks & 17 & 9 & \\
\hline
\end{tabular}


$\geq 8$ weeks between treatment completion and surgical resection was significantly associated with a higher rate of PCR $(p=0.03)$. A study by D. A. M. Sloothaak et al. in 2013 [15]. showed that Delaying surgery until 10-11 weeks after the end of RCT was significantly correlated with the complete histological response $(p=0.013)$. A recently published study using NCDB data provided the largest dataset focusing on the question of the interval from the end of CRT to surgery, and concurred with the published literature that an interval of more than 8 weeks is associated with increased rates of complete response [16]. In our study, the time between RCT and surgery was not correlated with a complete response ( $p$ $=0.3$ ). However, a delay of $\geq 8$ weeks was a predictor of downstaging $(\mathrm{p}=0.02)$. These findings are consistent with other recent studies, where they observed more downstaging and better surgical results with a delay of more than 8 weeks [17]. The largest published dataset to date [18], dealing with predictive factors of PCR after preoperative RCT in 23747 patients with rectal cancer, is consistent with those findings but, furthermore, offer additional variables that can help identify those patients most likely to respond (lower tumor grade, lower clinical $\mathrm{T}$ and $\mathrm{N}$ stage and higher radiation dose, while lack of health insurance was linked with a lower likelihood of PCR). Other studies have reported some variables that were not included in this study, such as low pretreatment CEA level [19-24], low CEA level after RCT [25-26], small pre- [27, 28] and post-treatment tumor size [29], pre-treatment tumor mobility on digital rectal examination [29], low clinical lymph node (N) classification [27], low tumor grade [30-31], shorter distance from the anal verge [11-30], low neutrophil to lymphocyte ratio [28], type of concurrent chemotherapy used [32] and higher radiation dose [33]. These factors are subjective parameters that are susceptible to inter-observer variations, and it is difficult to assess these factors in a retrospective study.

In conclusion, the identification of predictive factors for tumor response could have potential therapeutic applications. The increase in the rates of complete or partial histological responses has led to the emergence of the concept of conservative approaches such as a wait-and-see strategy [34]. Further studies are required to determine strategies for optimizing the oncological outcome on an individual basis.

\section{References}

1. Herszenyi L, Tulassay Z. Epidemiology of gastrointestinal and liver tumors. European review for medical and pharmacological sciences. 2010;14(4):249-58.

2. Heald RJ, Husband EM, Ryall RD. The mesorectum in rectal cancer surgery--the clue to pelvic recurrence? Br J Surg. 1982;69(10):613-6.

3. Cohen AM and Minsky BD. A phase I trial of preoperative radiation, proctectomy, and endoanal reconstruction. https:// www.ncbi.nlm.nih.gov/pubmed/?term $=\mathrm{A}+$ phase $+\mathrm{I}+$ trial $+\mathrm{o}$ $\mathrm{f}+$ preoperative + radiation $\% 2 \mathrm{C}+$ proctectomy $\% 2 \mathrm{C}+$ and + end oanal+reconstruction.+Arch+Surg+1990Arch Surg 1990; [ pp. 247-51 ].

4. Mohiuddin M RW, Marks GJ and Marks JW. . High-dose preoperative radiation and the challenge of sphincterpreservation surgery for cancer of the distal $2 \mathrm{~cm}$ of the rectum. https://www.ncbi.nlm.nih.gov/pubmed/?term=Highdose + preoperative + radiation + and + the + challenge + of + sphin cter-preservation + surgery + for + cancer + of + the + distal $+2+\mathrm{cm}$ +of+the+rectum1998; [ pp. 569-74 ].

5. Dhadda AS ZAaBE. Regression of rectal cancer with radiotherapy with or without concurrent capecitabine optimising the timing of surgical resection. Clin Oncol (R Coll Radiol). 2009; . pp. 23-31. p.

6. Benzoni E ID, Terrosu G, Bresadola V, Cojutti A, Cerato F, et al. Prognostic value of tumour regression grading and depth of neoplastic infiltration within the perirectal fat after combined neoadjuvant chemo-radiotherapy and surgery for rectal cancer. J Clin Pathol 2006; ;59 ((5), ):pp. 505-12. .

7. Park JH. YS, Yu CS, Kim JH, Kim TW and Kim JC. . Randomized phase 3 trial comparing preoperative and postoperative chemoradiotherapy with capecitabine for locally advanced rectal cancer. . Cancer 2011; ;117( (16),): pp. 3703-12. .

8. CC. SLaC. TNM seventh edition: what's new, what's changed: communication from the International Union Against Cancer and the American Joint Committee on Cancer.2010; . pp. 5336-39. p.

9. Dworak O, Keilholz L, Hoffmann A. Pathological features of rectal cancer after preoperative radiochemotherapy. International journal of colorectal disease. 1997;12(1):19-23.

10. de Campos-Lobato LF, Stocchi L, da Luz Moreira A, Kalady MF, Geisler D, Dietz D, et al. Downstaging without complete pathologic response after neoadjuvant treatment improves cancer outcomes for cIII but not cII rectal cancers. Annals of surgical oncology. 2010;17(7):1758-66.

11. Jonas J ME, Cavallaro A, Colasanti M, Sautter-Bihl ML, Frenzel H, et al. T-level downstaging and complete pathologic response after preoperative long-term radiochemotherapy for locally advanced rectal cancer. https://www.ncbi.nlm. nih.gov/pubmed/?term=T-level + downstaging + and + compl ete + pathologic + response + after + preoperative + long-term + radiochemotherapy+for+locally+advanced + rectal+cancer 2007; [65-71].

12. Das P SJ, Rodriguez-Bigas MA, Feig BW, Chang GJ, Wolff RA, , et al. Predictors of Tumor Response and Downstaging in Patients Who Receive Preoperative Chemoradiation for Rectal Cancer. Cancer 2007; ;109( (9):):1750-55.

13. Petrelli F SG, Sarti E and Barni S. Increasing the interval between neoadjuvant chemoradiotherapy and surgery in rectal cancer: a meta-analysis of published studies. . Ann Surg. 2016;; 263 ((3): ):458-64.

14. Habr-Gama A PR, Nadalin W, Nahas SC, Ribeiro U Jr, Silva E Sousa AH Jr, et al. . Long-term results of preoperative chemoradiation for distal rectal cancer correlation between final stage and survival. . J Gastro intest Surg 2005;; 9 ((1): ):90-101. .

15. Kalady MF DC-LL, Stocchi L, Geisler DP, Dietz D, Lavery IC, et al. . Predictive factors of pathologic complete response after neoadjuvant chemoradiation for rectal cancer. . Ann Surg 2009;; 250 ((4):):582-89.

16. Sloothaak DAM GD, Van Leersum NJ, Punt CJ, Buskens CJ, Bemelman WA, et al. . Optimal time interval between neoadjuvant chemoradiotherapy and surgery for rectal cancer. British Journal of Surgery. 2013;;100 ((7):):933-39. .

17. Probst CP BA, Aquina CT, Tejani MA, Wexner SD, GarciaAguilar J, et al. Extended intervals after neoadjuvant therapy in locally advanced rectal cancer: the key to improved tumor response and potential organ preservation. . J Am Coll Surg. 2015; ;221( (2): ):430-40. . 
18. Brown G, Evans J. Timing of surgery following chemoradiotherapy in rectal Cancer. Indian journal of medical and paediatric oncology : official journal of Indian Society of Medical \& Paediatric Oncology. 2014;35(4):2356.

19. Al-Sukhni E AK, Mattson DM, Gabriel E, Nurkin SJ. Predictors of Pathologic Complete Response Following Neoadjuvant Chemoradiotherapy for Rectal Cancer. . Ann Surg Oncol 2016;; 23 ((4): ):1177-86.

20. Zeng WG LJ, Wang Z, Zhang XM, Hu JJ, Hou HR, et al. . Clinical parameters predicting pathologic complete response following neoadjuvant chemoradiotherapy for rectal cancer. . Chin J Cancer 2015;;34 ((10): ):468-74.

21. Lee JH KS, Kim JG, Cho HM, Shim BY. . Preoperative chemoradiotherapy (CRT) followed by laparoscopic surgery for rectal cancer: predictors of the tumor response and the long-term oncologic outcomes. Int J Radiat Oncol Biol Phys. 2011; ;81( (2): ):431-8.

22. Wallin U RD, Lowry A, Luepker R, Mellgren A. . CEA: a predictor for pathologic complete response after neoadjuvant therapy for rectal cancer. Dis Colon Rectum 2013; ;56 ((7): ):859-68. .

23. Huh JW KH, Kim YJ. . Clinical prediction of pathological complete response after preoperative chemoradiotherapy for rectal cancer. . Dis Colon Rectum 2013;; 56 ((6): ):698-703.

24. Park YA, Sohn SK, Seong J, Baik SH, Lee KY, Kim NK, et al. Serum CEA as a predictor for the response to preoperative chemoradiation in rectal cancer. Journal of surgical oncology. 2006;93(2):145-50.

25. Farnault B M-ZL, De Chaisemartin C, Esterni B, Lelong B, Viret $\mathrm{F}$ et al. . Predictive factors of tumour response after neoadjuvant chemoradiation for locally advancedrectal cancer and correlation of these factors with survival. 2011; . 279-86. p.

26. Yang KL YS, Liang WY, Kuo YJ, Lin JK, Lin TC, et al. . Carcinoembryonic antigen (CEA) level, CEA ratio, and treatment outcome of rectal cancer patients receiving preoperative chemoradiation and surgery. 2013; . 43. p.

27. Kleiman A A-KA, Farsi A, Kezouh A, Vuong T, Gordon $\mathrm{PH}$, et al. . Normalization of CEA levels post-neoadjuvant therapy is a strong predictor of pathologic complete response in rectal cancer. J Gastrointest Surg 2015; ;19 ((6): ):1106-12.

28. Garland ML VR, Bunkley N, Pearse M, Bissett IP. Clinical tumor size and nodal status predict pathologic complete response following neoadjuvant chemoradiotherapy for rectal cancer. . Int J Colorectal Dis 2014; ;29 ((3): ):301-7 .

29. Kim IY YS, Kim YW. . Neutrophil-lymphocyte ratio predicts pathologic tumor response and survival after preoperative chemoradiation for rectal cancer. . BMC Surg 2014; ;14:: 94.

30. Park CH KH, Cho YB, Yun SH, Lee WY, Park YS, et al. Predicting tumor response after preoperative chemoradiation using clinic parameters in rectal cancer. World J Gastroenterol $2011 ; ; 17:: 5310-6$. .

31. Elmessiry MM AG, Elzeiny MM, Gebaly AA, Awad AT, Attia GE, et al. . Predictors of tumor response to neoadjuvant chemoradiation in locally advanced rectal cancer Egyptian patients. 2015; . 21-8. p.

32. Lin AY WW, Shia J, Minsky BD, Temple LK, Guillem JG, et al. Predictive clinicopathologic factors for limited response of $\mathrm{T} 3$ rectal cancer to combined modality therapy. Int $\mathrm{J}$ Colorectal Dis 2008; ;23( (3):):243-9.

33. Deng Y CP, Lan P, Wang L, Chen W, Cui L, et al. . Modified FOLFOX6 With or Without Radiation Versus Fluorouracil and Leucovorin With Radiation in Neoadjuvant Treatment of Locally Advanced Rectal Cancer: Initial Results of the
Chinese FOWARC Multicenter, Open-Label, Randomized Three-Arm Phase III Trial. J Clin Oncol ; .34( (27):): 3300-7.

34. Wiltshire KL WI, Swallow C, Oza AM, Cummings B, Pond GR, et al. . Preoperative radiation with concurrent chemotherapy for resectable rectal cancer: effect of dose escalation on pathologic complete response, local recurrence-free survival, disease-free survival, and overall survival. . Int J Radiat Oncol Biol Phys 2006; 64( (3): ):709-16. .

35. Mass M B-TR, Lambregts DM, Lammering G, Nelemans PJ, Engelen SM, et al. . Wait-and see policy for clinical complete responders after chemoradiation for rectal cancer. . J Clin Oncol ;. 2011; ;29((35): ):4633-40. .

\section{(i) (8)}

This work is licensed under a Creative Commons AttributionNon Commercial 4.0 International License. 